\title{
A FORMAÇÃO DA SUBJETIVIDADE MORAL NO PENSAMENTO DE MICHEL FOUCAULT
}

\author{
The formation of moral subjectivity in the thought of Michel Foucault
}

Bruno Camilo de Oliveira ${ }^{1}$

\begin{abstract}
RESUMO: O objetivo deste trabalho é apresentar a perspectiva de Michel Foucault sobre a formação da subjetividade moral segundo o seu texto intitulado "O uso dos prazeres e as técnicas de si". No referido texto, Foucault enfatiza que a ação moral não deve se constituir em atos conforme uma regra de conduta sustentada por conceitos morais, mas em atos conforme uma relação pura do sujeito com a sua sabedoria interna (subjetividade), relação essa que não deve ser compreendida como simplesmente uma "consciência de si" como sujeito moral, mas como uma "constituição de si" como sujeito moral. Considera-se neste artigo essa posição de Foucault sobre a formação da subjetividade moral para analisar o lugar do desejo na autonomia de si e das atitudes práticas, sobretudo se forem considerados: a experiência do sujeito como um processo em que tanto a subjetividade quanto os desejos são modificados ou anulados por normas ou leis específicas, estabelecidas em determinadas sociedades e cultura, quase sempre ligadas a normas de sexualidade; o poder do mais forte, na medida em que influencia instituições para difundir interesses na sociedade, corrompendo os desejos particulares dos indivíduos; as "técnicas de si", como práticas racionais e voluntárias que reprimem desejos, pelas quais os seres humanos determinam para si mesmos regras de conduta que correspondem a valores estéticos.
\end{abstract}

Palavras-chave: Subjetividade moral. Desejo. Experiência. Técnicas de si. Sexualidade.

\begin{abstract}
The objective of this work is to present Michel Foucault's perspective on the formation of moral subjectivity according to his text entitled "The use of pleasures and the techniques of self". In the referred text, Foucault emphasizes that moral action should not be constituted in acts according to a rule of conduct supported by moral concepts, but in acts according to a pure relation of the subject with his internal wisdom (subjectivity), a relationship that should not be understood as simply a "self-awareness" as a moral subject, but as a "constitution of the self" as a moral subject In this article, Foucault's position on the formation of moral subjectivity is considered to analyze the place of desire in the autonomy of oneself and of practical attitudes, especially if they are considered: the subject's experience as a process in which both subjectivity and desires are modified or annulled by specific norms or laws, established in certain societies and culture, almost always linked to norms of sexuality; the power of the strongest, insofar as it influences institutions to spread interests in society, corrupting the particular desires of individuals; the "techniques of

\footnotetext{
${ }^{1}$ Possui graduação em Filosofia (bacharelado) pela Universidade Federal do Rio Grande do Norte (2010), graduação em Filosofia (licenciatura) pela Universidade Federal do Rio Grande do Norte (2012), mestrado em Filosofia pela Universidade Federal do Rio Grande do Norte (2012) e doutorado em Filosofia pela Universidade Federal do Ceará (2018). Atualmente é professor adjunto da Universidade Federal do Semiárido. Tem experiência na área de Filosofia, com ênfase em Filosofia da Ciência. E-mail: bruno.camilo@ufersa.edu.br.
} 
self', as rational and voluntary practices that curb desires, by which human beings determine for themselves rules of conduct that correspond to aesthetic values.

Key-words: Moral subjectivity. Desire. Experience. Techniques of self. Sexuality.

\section{INTRODUÇÃO}

A constituição do sujeito moral é um processo histórico que envolve todo tipo de experiência de si a despeito das conjunturas histórico-sociais a que determinado indivíduo está submetido. A subjetividade expressa algo pessoal, idiossincrático, como as intuições pessoais, o desejo e os prazeres, mas a subjetividade também é capaz de expressar algo de impessoal, estranho, na medida em que é reprendida pela sua experiência com o mundo social e cultural. Tanto o saber reificado quanto o poder institucionalizado são causas de tal repressão da subjetividade, por meio de normas e valores, os quais estão em grande maioria relacionados a condenação do prazer do corpo e das formas de sexualidade distintas daquela que é aceita por determinada cultura como a forma correta. Essa repressão moral dos desejos e prazeres vai aos poucos moldando o indivíduo até que, após a formação da sua subjetividade moral, o indivíduo possa se tornar sujeito moral.

Partindo dessa concepção sobre a formação da subjetividade moral, o principal objetivo deste presente artigo é apresentar a maneira como Foucault (2004) considerou os saberes e poderes, sobretudo aqueles concedidos e praticados pelo cristianismo, capazes de reprimir a subjetividade. Um dos objetivos específicos é investigar a maneira como as formas de subjetividade foram capazes de resistir a influência desses saberes e poderes, constituindo, assim, uma história da resistência do indivíduo. Pretende-se também realizar uma análise sobre a perspectiva de Foucault acerca do lugar do desejo na autonomia de si e das atitudes práticas, tendo em vista a relação entre a noção de sexualidade e os valores cristãos. Pretende-se, por fim, refletir sobre a maneira como a noção de "sexualidade" esteve relacionada com a instauração de um conjunto de regras e de normas que fundamentaram a experiência da sexualidade, deixando clara a contribuição de Foucault para os estudos sobre a formação da subjetividade moral no século XX.

Para o cumprimento dos objetivos aqui propostos realiza-se, em um primeiro momento, uma síntese sobre o objetivo e as ideias de Foucault em seu texto "O uso dos prazeres e as técnicas de si", texto inicialmente publicado em 1984 e que compõe a reunião de textos intitulada Ética, sexualidade, política (FOUCAULT, 2004). Em um segundo momento é ressaltada a maneira como as técnicas de si e o cristianismo foram capazes de influenciar o comportamento sexual, sobretudo as atividades e prazeres que dele decorrem, para poder mostrar como, segundo Foucault, os desejos se tornaram objetos de uma preocupação e repressão moral. Após esses dois momentos, nas considerações finais, busca-se refletir sobre a resistência do indivíduo, em face a repressão do desejo, sobretudo ao concluir que o comportamento sexual foi sendo 
gradativamente considerado pertencente ao domínio de uma experiência moral, até o ponto em que, no século XX, a subjetividade moral do sujeito desejante foi modificada à luz de tal moral da sexualidade.

\section{O OBJETIVO DE “O USO DOS PRAZERES E AS TÉCNICAS DE SI”}

A proposta de Foucault (2004, p. 217) em "O uso dos prazeres e as técnicas de si” é realizar um estudo sobre um campo da História bastante complexo que compreende o período em que a subjetividade foi sendo gradativamente forçada "a se reconhecer como sujeito moral da conduta sexual". No referido texto a atenção de Foucault volta-se para o período crucial em que a subjetividade moral foi definida e transformada, a antiguidade, mais exatamente o período que vai desde o paganismo do pensamento grego clássico até a constituição da doutrina e da pastoral cristã da carne com os romanos. Contudo, é importante ressaltar que Foucault não possui como prerrogativa apenas a realização de um estudo histórico, como uma mera narrativa imparcial dos fatos, mas também uma análise crítica e filosófica acerca de um esquema de pensamento manifestado como efeito de diversos mecanismos de repressão específicos da sexualidade, na medida em que tais mecanismos de repressão equivalem a rejeitar do campo histórico o sujeito com a sua subjetividade e desejo.

Segundo Deleuze (2005, p. 109), a grande contribuição do estudo histórico de Foucault foi apresentar uma nova perspectiva sobre "a relação consigo", na medida em que buscou apresentar a relação consigo "como uma nova dimensão irredutível às relações de poder e às relações de saber". Esse é um ponto muito importante que sinaliza a real motivação de Foucault em realizar uma história da sexualidade. Isto é, no seio desse estudo histórico sobre a influência da sexualidade na formação da subjetividade moral Foucault realiza, então, o que se pode chamar de história da resistência da subjetividade, uma vez que ele reflete sobre os momentos da história em que houve o desenvolvimento do processo de constituição moral da sexualidade no sujeito desejante e sobre as rebeliões do sujeito desejante em face às repressões e imposições dos valores morais. Pois, para Foucault, qualquer tipo de reflexão sobre a subjetividade deve necessariamente estar associada a uma problematização da sexualidade - a maneira "como, no passado, os sujeitos manejaram as normas culturais que thes foram propostas, com base em uma prática de si” (NETO, 2017, p. 15) -, na medida em que a formação da subjetividade é dependente da influência cultural das normas, valores e padrões da sexualidade, segundo uma determinada conjuntura histórico-social.

Ora, de que maneira Foucault reconhece os sujeitos enquanto sujeitos sexuais? Para Foucault todas as condutas humanas são fundamentadas a partir do "desejo" ou de um "sujeito desejante", o qual está inserido em uma história da sexualidade como "experiência" (FOUCAULT, 2004, p. 193). O que é que Foucault quer dizer com o termo "experiência"? Segundo ele, entender a história da sexualidade como "experiência" é considerar a "experiência como uma correlação, em uma cultura, entre campos de saber, tipos de normatividade e formas de subjetividade", de modo que o indivíduo possa se reconhecer como 
sujeito de uma "sexualidade [...] que se articula a um sistema de regras cuja força de coerção é muito variável" (Ibidem). Em outras palavras, significa dizer que a "experiência" do sujeito nada mais é que a sua própria subjetividade e seus próprios desejos sendo constantemente formados de acordo com uma cultura, normas ou leis específicas, estabelecidas em uma determinada sociedade, quase sempre ligadas a normas de sexualidade (CANDIOTTO, 2016). Essas normas ou leis de conduta e comportamento assumem valores culturais para coibir ou anular certos tipos de desejos que porventura não estejam de acordo com a conduta sexual e moral considerada mais adequada.

Dessa forma, Foucault logo percebe que estudar a noção de "desejo" ou de "sujeito desejante" necessariamente implica em um estudo sobre a relação entre a história da sexualidade e a formação da subjetividade moral por meio da "experiência", o que não seria uma tarefa simples. Pois seria preciso analisar a formação e o desenvolvimento da experiência do sujeito desejante não apenas a partir do século XIX em diante, mas de uma coerente "genealogia" que possa considerar que a história da experiência do sujeito desejante é "consequente de uma longa tradição cristã, especificamente da influência platônica na experiência cristã da carne" (FOUCAULT, 2004, p. 194). Daí a necessidade de um estudo acerca da antiguidade, de uma correta genealogia do desejo, capaz de poder investigar a maneira pela qual os seres humanos acabaram sendo coagidos a exercer sobre si mesmos, assim como sobre os outros, uma "hermenêutica do desejo, propiciada por seu comportamento sexual, sem, no entanto, constituir seu domínio exclusivo" (Ibidem).

Além de uma genealogia do desejo nesses moldes, Foucault (2004) também se viu obrigado a estudar as manifestações do poder, em especial as "relações múltiplas, as estratégias abertas e as técnicas racionais que articulam o exercício dos poderes” (p. 195). Pois, há de se notar que determinadas ações não são fundamentadas a partir de um desejo puro, ou seja, aquele que é o resultado da vontade íntima, necessário somente ao ser e digno por si mesmo, mas de uma imposição da moral que acomete os indivíduos e molda a formação de suas subjetividades e atitudes desde o momento de seus nascimentos. Dessa forma Foucault se pôs a investigar e analisar de que maneira as manifestações do poder distorcem os desejos puros, a partir das estratégias e das técnicas racionais que articulam o exercício dos poderes. Ele descobre que os poderosos, por meio das instituições as quais estão determinados os seus poderes, como as instituições educacionais, religiosas, judiciárias e de saúde, conseguem interferir e alterar a natureza dos desejos puros e pessoais e divulgar, assim, os seus interesses. Esta influência dos poderosos, diz Foucault, acaba atingindo as condutas humanas, inclusive fundamentos de conduta e ações práticas como o prazer, os sentimentos e os sonhos. No que diz respeito a sexualidade, Foucault descobre que a sexualidade logo se tornou um importante instrumento de controle e de propagação do poder, na medida em que é capaz de mascarar o real interesse dos poderosos por meio de valores que coíbem os desejos e as ações dos indivíduos.

Falar dessa forma da sexualidade implicava libertar-se de um esquema de pensamento que era, então, bastante corrente: fazer da sexualidade uma invariante, e supor que, se ela 
assume, em suas manifestações, formas historicamente singulares, é por efeito de diversos mecanismos de repressão aos quais ela se encontra exposta em qualquer sociedade (FOUCAULT, 2004, p. 193).

É quando Foucault se depara com a relação do poder com algumas formas e modalidades da interação do sujeito consigo mesmo, através das quais o indivíduo se formava, se distinguia e se reconhecia como sujeito. Segundo Foucault (2004), o processo de assimilação de conteúdos e valores pelos indivíduos se dá por meio dos "jogos de verdade” (p. 195). Para ele os "jogos de verdade” são referidos às relações de poder, como base em práticas punitivas, que regularizam e legitimam a produção de significados naquilo que Foucault chama de "genealogia" ou "história do homem do desejo" (Ibidem). Em outras palavras, os jogos de verdade são saberes incutidos de autoridade por instituições e capazes de legitimar a repressão dos desejos por parte do próprio sujeito desejante. São os "jogos de verdade" que influenciam e determinam a relação do sujeito consigo mesmo, assim como a constituição de si próprio como sujeito.

\footnotetext{
Com efeito, segundo Foucault, a emergência (histórica) da obrigação de descobrir a verdade de nós mesmos em nós, bem como de a manifestar através de um discurso de confissão, nada mais é do que o efeito de uma série de técnicas de poder e de auto inserção em um regime de verdade que cava em nós mesmos o próprio espaço em que produz a verdade que somos chamados a descobrir e manifestar (LORENZINI, 2016, p. 66, tradução nossa).
}

Os jogos do verdadeiro e do falso, dos quais o ser se constitui historicamente como "experiência", podem ser percebidos pelos sujeitos que se rebelam contra a influência negativa do poder em suas subjetividades. É nesse ponto de rebelião que o sujeito considera uma análise do poder, para que o sujeito seja capaz de pensar o seu ser próprio, ao se perceber como um rebanho ou louco, se vendo como um doente, ao se refletir sobre si mesmo e perceber em que medida os jogos de verdade podem influenciar no seu próprio desejo. Poder perceber que a verdade divulgada pelos padrões morais de pensamento e conduta é, conforme insiste a abordagem nietzscheana, uma "metáfora", uma crença ilógica e fantasiosa, bastante infiel, que se confunde com um conhecimento e que cujo um dos objetivos é domar a subjetividade do sujeito desejante (NIETZSCHE, 1999, p. 55). Quando o sujeito desejante se rebela sobre os valores morais ele se torna capaz de pensar de forma diferente da que se pensa comumente e de perceber que pensar de forma diferente da que se pensa é indispensável para refletir e criar seus próprios valores, afirmar seus próprios desejos. Deste modo, é necessário entender a importância do pensamento crítico e da educação para poder discernir quais ações os sujeitos estão praticando por seus próprios desejos e quais ações praticam em prol do desejo dos mais poderosos, para que possam reconhecer os seus próprios desejos não corrompidos pelos mais fortes. 
Em suma, a análise foucaultiana da história do desejo, em Foucault (2004), tem como foco a lenta formação, durante a antiguidade, de uma hermenêutica de si. O motivo da sua preocupação com os "jogos de verdade" foi a sua vontade em poder evidenciar alguns elementos capazes de servir para uma história da verdade, ou seja, uma história dos “"jogos de verdade’, dos jogos do verdadeiro e do falso através dos quais o ser se constitui historicamente como experiência, [...] como podendo e devendo ser pensado" (p. 195). Em "O uso dos prazeres e as técnicas de si" Foucault buscou entender por meio de quais "jogos de verdade" o ser humano se reconheceu como sujeito de desejo e se pôs a pensar a si mesmo, ao refletir sobre si mesmo como ser vivo, como louco.

\section{A SEXUALIDADE COMO CRITÉRIO MORAL}

Uma vez identificado que a noção de sexualidade possui total influência sobre a formação da subjetividade moral e, consequentemente, sobre o desejo, por meio dos jogos de verdade, Foucault se pôs, então, a analisar a seguinte questão: por que o comportamento sexual e as atividades e prazeres que dele decorrem se tornaram objetos de uma preocupação moral? De onde vem essa necessidade de um certo cuidado ético em relação às condutas alimentares ou o cumprimento dos deveres cívicos, conforme pode ser percebido em algumas sociedades e em certos grupos cívicos, em que parece ser muito importante a atenção moral dirigida aos domínios da sexualidade? Como, quando e por que a atividade sexual passou a ser constituída como domínio moral? Segundo Foucault (2004), essa problematização esteve ligada ao que ele chama de "artes da existência" ou "técnicas de si" (p. 198), isto é, práticas racionais voluntárias pelas quais os seres humanos não apenas determinam para si mesmas regras de conduta, mas também "buscam transformar-se, modificar-se em seu ser singular, e fazer de sua vida uma obra que seja portadora de certos valores estéticos e que corresponda a certos critérios de estilo" (p. 198-199). Pois, como ressalta Ortega (1999, p. 44-45), "se em seus últimos trabalhos Foucault fala do sujeito, não se trata do sujeito epistêmico ou genealógico, mas de um sujeito ético, constituído através de práticas de si”. Segundo Foucault, tais artes da existência ou técnicas de si acabaram gradativamente perdendo sua autonomia e estima ao serem associadas ao cristianismo, em princípio ao exercício de um poder pastoral e, mais adiante, às práticas de cunho educativo e curandeiro.

De acordo com Foucault (2004, p. 200), foram as "técnicas de si" que começaram a valorizar a atividade e os prazeres sexuais, na antiguidade, o que resultou em uma primeira formulação dos critérios de uma "estética da existência". Todavia, é importante notar que tal valoração da sexualidade não possuía um caráter pejorativo, como se a sexualidade representasse algo repugnante ou que merecesse ser escondido. Com o surgimento do cristianismo as "técnicas de si" ganharam uma nova roupagem moral e passaram a atribuir um valor pejorativo ao ato sexual, associando-o "ao mal, ao pecado, à queda, à morte, enquanto a antiguidade o teria dotado de significações positivas" (p. 201). Diferentemente como ocorria nas sociedades gregas ou romanas pagãs, o cristianismo delimitava o parceiro legítimo e apenas teria aceitado o casamento 
monogâmico cuja conjugalidade deveria ter como finalidade exclusiva a procriação. O casamento voltado exclusivamente para a procriação é fundamentado na ideia de que aos olhos de Deus o sexo serve apenas para a reprodução da espécie, não para a satisfação do desejo ou prazer sexual. Outra diferença importante entre o cristianismo e o paganismo é a consideração sobre as relações entre indivíduos do mesmo sexo: o cristianismo as desqualificou e as excluiu rigorosamente, enquanto que os pagãos as exaltou - os gregos as praticavam e os romanos as aceitavam ao menos entre homens e rapazes. Além disso, diferentemente da moral pagã, o cristianismo atribuía um alto valor moral e espiritual ao jejum sexual, à castidade sacerdotal e à virgindade. Em suma, as questões em torno da sexualidade eram completamente distintas entre pagãos e os cristãos, sendo questões muito mais toleráveis e naturais para os pagãos do que para os cristãos.

Não se deve concluir, entretanto, que a moral do sexo surgiu pela primeira vez entre os gregos e romanos pagãos. Uma reflexão moral bastante primitiva já existia entre os mais antigos, a exemplo de "uma particularidade dos egípcios, dos germanos e dos judeus" (VEYNE, 2009, p. 21), que consideraram a temática da austeridade sexual em torno dos prazeres do corpo, do casamento e das relações entre homens. Esse cuidado com a austeridade manteve-se através dos tempos. Por outro lado, foi no cristianismo que "as proibições" e "as obrigações" se tronaram "mais coercitivas, que, de forma geral, as morais desenvolveram as mais insistentes exigências de austeridade" (FOUCAULT, 2004, p. 208). A história do cristianismo ou da Europa moderna seria suficiente para mostrar exemplos dessas exigências de austeridade, o que, segundo Foucault, não parece ter ocorrido na antiguidade.

É importante ressaltar que na antiguidade a moral do sexo se dirigiu apenas aos homens, não às mulheres.

\footnotetext{
Uma moral pensada, escrita, ensinada por homens e dirigida aos homens, evidentemente livres. Moral viril, consequentemente, na qual as mulheres apenas apareciam a título de objetos, ou, no máximo, como parceiras que convém formar, educar e vigiar, quando elas estão sob seu poder e das quais, em contrapartida, é preciso abster-se, quando estão sob o poder de um outro (pai, marido, tutor) (FOUCAULT, 2004, p. 209).
}

Este é um ponto bastante notável dessa reflexão moral da antiguidade: quer dizer, ela não almeja construir um padrão de comportamento e um conjunto de regras válidas para os dois sexos, ao contrário, ela "é uma elaboração da conduta masculina feita do ponto de vista dos homens, para dar forma à conduta deles" (Ibidem). Isto é, a reflexão moral da antiguidade não se dirige aos homens tendo em vista a vigilância ou adequação de suas atitudes em relação ao que preconizam o código moral, os costumes e as regras religiosas, mas tendo em vista o suposto direito dos homens ao poder, dominação, autoridade e liberdade. Inclusive no que diz respeito a não condenação dos prazeres dos homens, "em uma vida matrimonial na qual, no exercício de um poder marital, nenhuma regra ou costume impede o homem de ter relações extraconjugais" e, até mesmo nas relações de homens com homens que, "pelo menos de certos limites, são 
admitidas, corriqueiras e até valorizadas" (FOUCAULT, 2004, p. 209-210). É preciso conceber esses temas de austeridade sexual, não como uma tradução ou comentário de proibições profundas e essenciais, como ocorreu com o cristianismo, mas como uma constatação do exercício do poder e dos privilégios dos homens.

\section{CONSIDERAÇÕES FINAIS}

Pode-se dizer que Foucault define a moral como um conjunto de valores ou códigos morais que agem sobre o comportamento e a ação dos indivíduos e que são impostos às pessoas e aos grupos mediante instituições como as igrejas, as escolas e a família. Além de mostrar que a moral é fundamentada em um processo que relaciona o comportamento humano e a imposição das regras e valores, Foucault tem a pretensão de investigar a maneira pela qual as pessoas se relacionam com tais princípios de conduta, na medida em que elas optam por obedecer ou resistir a um conjunto de valores. A expectativa de Foucault é que um estudo sobre a história da sexualidade seja suficiente para apontar a maneira como as pessoas agem de acordo com um sistema prescritivo de normas de conduta que é determinado pela cultura e do qual as pessoas têm uma vaga consciência. Foucault chama esse nível dos fenômenos de "moralidade dos comportamentos" (FOUCAULT, 2004, p. 211).

É preciso ressaltar ainda que além da regra de conduta e da conduta que se pode comparar com essa regra, há também uma preocupação de Foucault em entender a forma como o indivíduo se torna por si próprio sujeito moral, se comportando e agindo segundo o que prescrevem os códigos morais. Pois, uma vez impostos determinados padrões de conduta e tipos de ações os indivíduos possuem diferentes maneiras de se conduzir moralmente, isto é, maneiras distintas do indivíduo agir não como sujeito que afirma suas próprias convicções, mas como sujeito moral de suas ações. Tais maneiras de agir constituem o que se pode chamar de formação da subjetividade moral ou de determinação da substância ética, isto é, "a maneira pela qual o indivíduo deve constituir este ou aquele aspecto dele próprio como matéria principal de sua conduta moral" (FOUCAULT, 2004, p. 212). O aparecimento da substância ética acaba por interferir no domínio dos desejos, fazendo emergir uma forma de combate contra eles, tendo em vista a resistência das tentações. $\mathrm{O}$ que constitui a subjetividade moral são exatamente a vigilância e a luta do indivíduo em relação aos seus desejos, sendo as tarefas de vigilância e luta os maiores representantes da prática moral do que a própria ação moral.

Para Foucault existem variadas maneiras de elaborar um trabalho ético sobre si mesmo, não somente no que diz respeito a capacidade de modificar o seu comportamento segundo um determinado padrão de conduta, mas também de tentar fazer de si mesmo um indivíduo moral. "Assim”, diz Foucault (2004, p. 213), "a austeridade sexual pode ser praticada através de um longo trabalho de aprendizagem, de memorização e de assimilação de um conjunto sistemático de preceitos, e através do controle regular da conduta na exatidão com que essas regras são aplicadas". Em outras palavras, a austeridade sexual pode ser 
praticada quando ocorrem uma renúncia dos prazeres e uma decifração dos desejos. Portanto, não basta realizar uma ação conforme preconiza uma regra ou padrão ou valor para que ela possa ser reconhecida como moral, é preciso também que além de uma relação entre a ação, o real e o código moral que haja ainda uma relação entre a ação e a subjetividade de quem a pratica, não simplesmente como

\begin{abstract}
"Consciência de si", mas constituição de si como "sujeito moral", na qual o indivíduo circunscreve a parte dele próprio que constitui esse objetivo de prática moral, define a sua posição em relação ao preceito que ele acata, determina para si um certo modo de ser que valerá como cumprimento moral dele mesmo e, para realizar-se, age sobre ele mesmo, levando-o a se conhecer, a se controlar, a pôr-se à prova, a se aperfeiçoar e a se transformar (FOUCAULT, 2004, p. 214).
\end{abstract}

De acordo com Foucault, não existe uma determinada ação moral que não se refira à unidade de uma conduta moral consigo mesma. A conduta moral deve necessariamente exigir do sujeito moral a constituição de si mesmo como sujeito moral. Para ele, sem modos de subjetivação, ascética ou práticas de si não existe a possibilidade do sujeito se constituir enquanto sujeito moral. Tais modos de atividades sobre si são indissociáveis de qualquer ação moral.

A história das condutas morais será, portanto, a história dos modos como os sujeitos se constituem a si mesmos como sujeitos de condutas morais. Uma história dos modelos que contribuíram para o desenvolvimento de relações para consigo, de reflexões sobre si, do conhecimento sobre si e das mudanças que se busca para consigo. Eis, então, o que Foucault vai chamar de história da "Ética" e da "ascética", entendida como "história das formas de subjetivação moral e das práticas de si que são destinadas a garantila" (Ibidem). A subjetividade moral se desenvolve, nessas condições, segundo uma maneira quase jurídica em que o sujeito moral considera uma ou várias leis que ele deve se submeter, sob pena de sofrer um castigo caso cometa alguma falta.

Embora a necessidade de respeitar as leis e os costumes, em tais reflexões morais na antiguidade grega ou greco-romana, seja comumente enfatizada, no que diz respeito a conduta moral o mais importante está na atitude que faz com que tais leis sejam respeitadas, não no conteúdo propriamente das leis. Dessa forma, a ênfase dada por Foucault à formação da subjetividade moral é na relação do indivíduo consigo mesmo, na medida em que não se deixa

Levar pelos apetites e prazeres, que permite proteger-se contra seu domínio e superioridade, manter seus sentidos em um estado de tranquilidade, manter-se livre de qualquer escravização interna em relação às paixões, e atingir um modo de ser que pode ser definido pelo gozo pleno de si mesmo ou pela perfeita soberania sobre si mesmo (FOUCAULT, 2004, p. 216). 
Além do mais, se as ações práticas são fundamentadas a partir do desejo, então aquelas ações cuja fundamentação encontra-se em desejos pessoais, isto é, desejos particulares apenas ao sujeito em si, são mais puras por se realizarem por meio daquilo a que se refere a si mesma ou ao próprio sujeito. Seguindo esse raciocínio Foucault (2004) está convencido que as ações que são realizadas com base em um desejo próprio do indivíduo são ações puras, enquanto que aquelas que são realizadas por determinação de um desejo apreendido para si, mas não próprio de si, são impuras em relação ao sujeito em si. E caso seja o interesse estudar algo que já está por si fundamentado em ações, como é o caso dos costumes, da sexualidade e dos modos de agir e pensar sobre algo, será preciso estudar todo o percurso histórico das "experiências", ou seja, a forma como os indivíduos puderam ser reconhecidos como sujeitos de uma ação impura. Desta forma, será preciso refletir sobre a "sexualidade" e outras condutas de forma distorcida a partir de um sistema de regras na cultura ou em campos do saber que distorcem as formas de subjetividade, no decorrer da história. Será preciso ainda compreender em que medida os seres humanos passaram a se reconhecer enquanto sujeitos do desejo e como é possível que os seus desejos sejam influenciados por vontades externas ao próprio sujeito.

Assim, o objetivo de Foucault não é realizar uma simples história do desejo, mas analisar as práticas através das quais os indivíduos perderam a atenção do desejo consigo mesmo, para que possam se reconhecerem e se assumirem como sujeitos de desejo, estabelecendo de si para consigo mesmos certa relação que lhes permite descobrir, no desejo, a verdade de seu ser.

O estudo do desejo permite analisar as formas e as modalidades da relação consigo mesmo, por meio das quais o indivíduo se constitui e se reconhece como sujeito, ou seja, perceber o modo pelo o qual os indivíduos foram levados a exercer sobre eles mesmos, e sobre os outros, uma hermenêutica do desejo, uma escamoteação da própria vontade subjetiva, que não cumpre com suas próprias necessidades. Para Foucault, esta hermenêutica está intimamente ligada à sexualidade. Aliás, está bastante associada ao comportamento sexual, sem, no entanto, constituir seu domínio exclusivo. Pois, ao estudar a história da sexualidade em "O uso dos prazeres e as técnicas de si”, Foucault percebeu que um dos momentos históricos cruciais foi justamente quando a tradição cristã, dos séculos XIX e XX, impôs seus valores e condutas acerca do desejo e da sexualidade. Além da religião, é possível também perceber em outras instituições a conduta imposta por elas aos indivíduos, de forma a conseguir moldar os desejos puros das pessoas e formar a subjetividade moral de cada uma delas.

Uma das contribuições de Foucault para o século XX e séculos seguintes é a sua ênfase na importância de superar a necessidade de uma moralidade no sentido normativo e prescritivo. Não se trata de um esforço para substituir uma moralidade prescritiva por uma outra mais branda, relativa, permissível, mas de um esforço para apontar que os princípios da moralidade não são absolutos e universais. Foucault esteve muito mais interessado em uma moralidade em que houvesse a possibilidade de afirmação do sujeito 
desejante, uma moralidade em que não houvesse espaço para o "niilismo" (NIETZSCHE, 2007, p. 35), isto é, a negação de si pela aceitação consciente ou inconsciente de obstáculos que impedem o próprio desenvolvimento de si. Se houvesse a possibilidade de falar em uma moralidade foucaultiana então poderia ser dito que se trataria de uma moralidade em que consideraria apenas o relacionamento do eu consigo mesmo (DAVIDSON, 2006). Uma moralidade referente a apenas a reflexividade do self, "aquela parte do self que se 'dobra' sobre si mesma” (SMITH, 2015, p. 144, grifo nosso, tradução nossa). Não existe para Foucault uma essência do sujeito, mas um processo reflexivo em que o indivíduo pode se submeter: ele pode se sujeitar às normas pré-estabelecidas ou pode considerar o self enquanto uma forma de relação consigo mesmo.

\section{REFERÊNCIAS}

CANDIOTTO, C. Práticas de subjetivação e experiência da sexualidade em M. Foucault: sobre O uso dos prazeres e O cuidado de si. In: RESENDE, H. (org.). Michel Foucault: política - pensamento e ação. Belo Horizonte: Autêntica Editora, 2016. p. 77-94.

DAVIDSON, A. Ethics as ascetics: Foucault, the history of ethics, and ancient thought. In: GUTTING, G. (ed.). The Cambridge companion to Foucault. 2th ed. New York: Cambridge University Press, 2006. 123-148.

DELEUZE, G. Foucault. São Paulo: Brasiliense, 2005.

FOUCAULT, M. O uso dos prazeres e as técnicas de si. In: FOUCAULT, M. Ética, sexualidade, política. Rio de Janeiro: Forense universitária, 2004. p. 192-217. (Ditos e escritos; V).

LORENZINI, D. Foucault, regimes of truth and the making of subject. In: CREMONESI, L. et al. (ed.). Foucault and the making of subjects. London: Rowman \& Littlefield, 2016. p. 63-75.

NETO, J. L. F. A analítica da subjetivação em Michel Foucault. Revista polis e psique, Porto Alegre, v. 7 , n. 3, p. 7-25, 2017. Disponível em: https://seer.ufrgs.br/PolisePsique/article/view/76339. Acesso em: 01 out. 2020.

NIETZSCHE, F. W. Genealogia da moral: uma polêmica. São Paulo: Companhia das Letras, 2007. 
NIETZSCHE, F. W. Sobre verdade e mentira no sentido extra-moral (1873). In: LEBRUN, G. (ed.). Friedrich Nietzsche: obras incompletas. São Paulo: Nova Cultural, 1999. p. 51-60. (Os pensadores; 32).

ORTEGA, F. Amizade e estética da existência em Foucault. Rio de Janeiro: Graal, 1999.

SMITH, D. Foucault on ethics and subjectivity: "care of the self" and "aesthetics of existence". Foucault studies, Copenhagen, n. 19, p. 135-150, jun. 2015. Disponível em: https://doi.org/10.22439/fs.v0i19.4819. Acesso em: 02 out. 2020.

VEYNE. P. O império romano. In: VEYNE. P. (org.). História da vida privada 1: do império romano ao ano mil. São Paulo: Companhia das Letras, 2009. p. 18-212. 